\title{
Penggunaan Kacang Hias (Arachis pintoi) sebagai Biomulsa pada Budidaya Tanaman Tomat (Lycopersicon esculentum M.)
}

\author{
The Use of Arachis pintoi as Biomulch in Tomato Cultivation \\ M. A. Chozin ${ }^{1}$, Juang G. Kartika ${ }^{{ }^{*}}$, dan Raisa Baharudin ${ }^{1}$ \\ Diterima 4 Juni 2014/Disetujui 7 Oktober 2014
}

\begin{abstract}
The objective of this study was to determine the effect of Arachis pintoi planting as bio-mulch on growth and yield of tomato and weed growth. An experiment was conducted at Cikabayan, University Farm of IPB, from January to June 2010. The research was arranged in a randomized Complete Block Design with 3 replications. The results of this study showed the growth and speed of coverage of $\underline{A}$. pintoi in this experiment was relatively slow. The use of mulch improved the growth, yield components and production of tomatoes. The best mulch was a plastic mulch. The best planting period of $\underline{A}$. pintoi as bio-mulch was 7 and 10 weeks before planting.
\end{abstract}

Key words: bio-mulch, growth, silver black plastic mulch, yield

\begin{abstract}
ABSTRAK
Penelitian ini bertujuan untuk mengetahui pengaruh penanaman Arachis pintoi sebagai biomulsa dalam menghambat pertumbuhan gulma dan meningkatkan pertumbuhan dan produksi tanaman tomat. Penelitian dilaksanakan di kebun percobaan Cikabayan-UF IPB, Darmaga Bogor dari Januari sampai Juni 2010. Percobaan menggunakan Rancangan Kelompok Lengkap Teracak (RKLT) faktor tunggal, yaitu dengan 4 perlakuan waktu tanam $A$. pintoi dan 2 pembanding: M0 (monokultur tanaman tomat tanpa mulsa), M1 (monukultur tanaman tomat dengan mulsa plastik hitam perak), M2 (10 minggu A. pintoi sebelum tomat ditanam), M3 (7 minggu A. pintoi sebelum tomat ditanam), M4 (4 minggu A. pintoi sebelum tomat ditanam), dan M5 (1 minggu A. pintoi sebelum tomat ditanam). Hasil percobaan menunjukkan bahwa persentase tumbuh dan kecepatan penutupan $A$. pintoi relatif lambat. Tanaman tomat yang ditanam dengan biomulsa $A$. pintoi 10 dan 7 minggu sebelum tanam menunjukkan persentase tumbuh dan pertumbuhan yang lebih baik dibandingkan perlakuan mulsa plastik hitam perak (MPHP) maupun perlakuan tanpa mulsa. Perlakuan biomulsa A. pintoi 10 dan 7 minggu sebelum tanam (MSbT) serta perlakuan mulsa plastik hitam perak (MPHP) meningkatkan komponen pertumbuhan dan produksi buah tomat.
\end{abstract}

Kata kunci: biomulsa, pertumbuhan, mulsa plastik hitam perak, produksi

\section{PENDAHULUAN}

Tomat merupakan komoditi sayuran buah yang penting di Indonesia karena banyak dibutuhkan masyarakat untuk berbagai keperluan baik dalam keadaan buah segar maupun hasil olahan. Menurut Kartapradja dan Djuariah (1992), buah tomat saat ini merupakan salah satu komoditas hortikultura yang bernilai ekonomis tinggi.

Perbaikan produksi harus terus dilakukan untuk mendapatkan hasil yang optimum dan berkelanjutan. Diantara teknik budidaya yang ramah lingkungan serta mampu meningkatkan produksi adalah pemupukan pada waktu tertentu dan lokasi yang spesifik. Misalnya untuk tanaman tomat yang ditanam di lahan inseptisues dengan status hara kalium sangat rendah, maka perlu dilakukan pemupukan sebesar $180 \mathrm{~K}_{2} \mathrm{O} \mathrm{kg} \mathrm{ha}{ }^{-1}$ (Izhar dan Susila, 2010). Penggunaan mulsa organik/biomulsa juga termasuk aplikasi teknik budidaya yang ramah lingkungan. Mulsa organik berasal dari bahan-bahan alami yang mudah terurai antara lain sisa-sisa tanaman seperti jerami

\footnotetext{
${ }^{1}$ Departemen Agronomi dan Hortikultura, Fakultas Pertanian, Institut Pertanian Bogor

(Bogor Agricultural University), Jl. Meranti, Kampus IPB Darmaga, Bogor 16680, Indonesia

Telp.\&Faks.62-251-8629353. *Email korespondensi: ika_juang@yahoo.com
} 
dan alang-alang. Mulsa organik bermanfaat dalam konservasi tanah, menghambat pertumbuhan tanaman pengganggu, dan memiliki efek menurunkan suhu tanah. Selain itu mulsa organik dapat berupa tanaman penutup tanah. Penggunaan tanaman penutup tanah sebagai mulsa dapat menekan pertumbuhan gulma. Selain itu, tanaman penutup tanah dapat berfungsi melindungi tanah terhadap daya merusak aliran air dan memperbaiki penyerapan air ke dalam tanah (Rosliani et al., 2002).

Tanaman penutup tanah jenis kacangkacangan (Leguminosae) memiliki sifat yang menguntungkan bagi tanaman. Tanaman penutup tanah kacangan yang telah menutup tanah dapat menekan pertumbuhan gulma. Rosliani et al. (2002) melaporkan bahwa kacang tanah yang digunakan sebagai tanaman penutup tanah selain dapat meningkatkan produksi mentimun, juga mampu menekan erosi tanah sebesar 35\% dan perkembangan gulma.

Kacang hias (A. pintoi) merupakan tanaman tahunan golongan kacang-kacangan (Leguminosae) yang tumbuh memiliki potensi dalam menambat nitrogen dari udara. Berdasarkan sifat-sifat tersebut $A$. pintoi sangat baik ditanam sebagai biomulsa pada produksi sayuran dan buah, tanaman penutup tanah, bahan hijauan makanan ternak, ataupun sebagai tanaman hias (Kartika et al., 2009).

Penggunaan $A$. pintoi juga dapat dilakukan pada lahan pertanian intensif (hortikultura). Pada lahan pertanian intensif tanaman ini selain sebagai tanaman penutup tanah yang dapat menambah nitrogen dalam tanah, digunakan sebagai mulsa serta dapat menekan pertumbuhan gulma dan penyakit. Dari hasil penelitian di Costa Rica, $A$. pintoi mampu melindungi tanaman tomat dari infeksi yang disebabkan nematoda Meloidogyne arabicide (Balittan, 2004).

Penanaman kacang hias diharapkan dapat menutupi tanah sehingga dapat menekan pertumbuhan gulma pada tanaman tomat. Berkurangnya persaingan terhadap gulma diharapkan dapat meningkatkan pertumbuhan tanaman tomat yang lebih baik sehingga mampu menghasilkan produksi yang meningkat dan kualitas tomat yang baik. Selain itu dapat memperbaiki sifat fisik dan kimia tanah.

Penelitian ini bertujuan untuk mengetahui pengaruh penanaman $A$. pintoi sebagai biomulsa dalam menghambat pertumbuhan gulma dan meningkatkan pertumbuhan dan produksi tanaman tomat.

\section{BAHAN DAN METODE}

Penelitian dilaksanakan di kebun percobaan Cikabayan, UF - IPB, Darmaga Bogor. Areal penelitian bertopografi datar dengan elevasi $250 \mathrm{~m}$ dpl dan curah hujan rata-rata $3300 \mathrm{~mm}$ tahun $^{-1}$. Penelitian dimulai Januari-Juni 2010.

Bahan yang digunakan terdiri atas benih tomat bersertifikasi varietas Permata F1 dan stek batang A. pintoi, pupuk kandang, kapur, kasting, furadan, Rootone-F, Gandasil-D sebagai starter solution, Gandasil-B, NPK Mutiara dan pestisida kimiawi. Alat yang digunakan adalah peralatan tanam, alat ukur, gelas ukur, timbangan analitik, alat tulis, mulsa plastik hitam perak (MPHP), tray persemaian, bak plastik.

Percobaan menggunakan Rancangan Kelompok Lengkap Teracak (RKLT) faktor tunggal, yaitu dengan 4 perlakuan waktu tanam $A$. pintoi dan 2 pembanding: M0 (monokultur tanaman tomat tanpa mulsa), M1 (monukultur tanaman tomat dengan MPHP), M2 (70 hari $A$. pintoi sebelum tanam tomat), M3 (49 hari $A$. pintoi sebelum tanam tomat), M4 (28 hari $A$. pintoi sebelum tanam tomat), dan M5 (7 hari $A$. pintoi sebelum tanam tomat). Setiap perlakuan diulang sebanyak tiga kali sehingga terdapat 18 satuan percobaan. Masing-masing perlakuan menempati petak berukuran $5 \mathrm{~m}$ x $1.2 \mathrm{~m}$.

Tanah diolah sedalam $20 \mathrm{~cm}$, digaru, dan diratakan dengan cangkul dua minggu sebelum penanaman $A$. pintoi. Pemberian pupuk kandang, kapur, dan pupuk dasar dilakukan setelah pembuatan bedengan. Penanaman A. pintoi dilakukan sesuai perlakuan yaitu 7, 28, 49, 70 hari sebelum tanam (HSbT) tanaman tomat sebagai tanaman utama. Pemasangan mulsa plastik pada perlakuan MPHP diterapkan satu minggu sebelum penanaman tomat.

Bahan tanam A. pintoi yang digunakan berupa stek batang yang berasal dari Kebun Percobaan Cikabayan. Stek berukuran $15 \mathrm{~cm}$ atau empat ruas direndam selama satu malam dalam air yang telah dicampur dengan $1 \mathrm{~g}$ Rootone dalam 1 liter air. Stek tersebut ditanam dengan jarak antar stek $15 \mathrm{~cm}$ x $15 \mathrm{~cm}$

Pengamatan vegetatif tanaman tomat dilakukan terhadap variabel tinggi tanaman, jumlah daun, (2-5 MST), umur berbunga, jumlah ruas (2-7 MST), panjang ruas (2-7 MST), dan panjang ruas (2-7 MST). Pengamatan komponen hasil tomat dilakukan pada parameter jumlah buah, bobot panen, bobot per buah, bobot buah 
layak pasar, dan bobot buah tidak layak (penyakit/ ulat).

Pengamatan pada $A$. pintoi meliputi persentase tumbuh, persentase penutupan. Pengamatan pada gulma meliputi jenis gulma yang tumbuh, jumlah gulma, bobot kering, dan dominansi gulma. Analisis tanah sebelum dan sesudah percobaan secara komposit dengan mengambil tanah sedalam $\pm 20 \mathrm{~cm}$ dari beberapa titik pada masing-masing perlakuan.

\section{HASIL DAN PEMBAHASAN}

Hasil analisis Laboratorium Balai Penelitian Tanah menunjukkan bahwa kondisi tanah sebelum penelitian tergolong masam $\left(\mathrm{pH} \mathrm{H}_{2} \mathrm{O}\right.$ 5.00) dengan kapasitas tukar kation rendah (17.56 me $100 \mathrm{~g}^{-1}$ ). Menurut data Stasiun Klimatologi Darmaga, jumlah curah hujan rata-rata selama penelitian berlangsung adalah sebesar 300.7 $\mathrm{mm} /$ bulan dengan suhu rata-rata $23.2-31.8^{\circ} \mathrm{C}$ dan kelembaban rata-rata $84.3 \%$.

Hasil analisis tanah yang dilakukan setelah perlakuan menunjukkan bahwa C-organik dan Ntotal pada perlakuan biomulsa $A$. pintoi meningkat dua kali lebih tinggi. Namun, nilai rasio $\mathrm{C} / \mathrm{N}$ dalam tanah pada perlakuan biomulsa $A$. pintoi tidak menunjukkan perubahan. Peningkatan yang sangat tinggi terjadi pada kandungan $\mathrm{P}_{2} \mathrm{O}_{5}$ dan $\mathrm{K}_{2} \mathrm{O}$ pada semua perlakuan terutama perlakuan mulsa plastik hitam perak masing-masing 136.0 dan 137.0 ppm.

Kendala dalam penanaman A. pintoi yaitu banyaknya $A$. pintoi yang mengalami kekeringan dan mati pada 4 minggu sebelum tanam (MSbT) tomat sehingga dilakukan penanaman kembali. Salah satu cara untuk mengurangi kematian $A$. pintoi adalah dengan penyiraman. Hama yang menyerang adalah lundi. Lundi memotong akarakar pintoi tepat di bawah permukaan tanah. Serangan penyakit yang ada meliputi bercak daun yang disebabkan oleh cendawan Cercospora personata.

Transplanting tomat dilakukan saat bibit tomat berumur 35 hari. Selama pembibitan, tanaman terkena penggorok daun (Liriomyza spp.). Persentase hidup tanaman tomat di lapang hingga 3 MST mencapai 84\%. Pada awal penanaman tomat persentase kematian terbanyak pada perlakuan mulsa plastik hitam perak (MPHP) sebesar $25 \%$ sedangkan pada perlakuan tanpa mulsa sebesar 23\%. Perlakuan biomulsa $A$. pintoi 70, 49, 28, dan 7 HSbT mampu menekan persentase kematian bibit hingga sebesar 20, 13.3, 8.3, dan $6.7 \%$.

Hama yang menyerang tanaman tomat selama di lapangan adalah belalang hijau (Nympahea sp.), rayap (Macrotermes gilvus), dan ulat buah tomat (Helicoperva armigera Pengendalian hama dilakukan dengan cara pemberian Decis 2.5 EC (Deltamethrin) pada 2 MST. Sedangkan penyakit yang menyerang adalah layu Fusarium (Fusarium oxysporum Schlecth) dan bercak coklat. Gejala yang ditimbulkan adalah pucatnya tulang-tulang daun, menguningnya daun-daun bagian bawah, dan terjadi kelayuan tanaman (Semangun, 1994). Penyakit Fusarium menyerang tanaman rata-rata pada 2 MST. Serangan tersebut lebih banyak terjadi pada perlakuan tanpa mulsa dengan persentase kejadian sebesar $31 \%$, sedangkan pada perlakuan lain menunjukkan nilai yang lebih rendah (Tabel 1).

Tanaman tomat mulai berbunga saat 5 MST. Selama periode pembungaan, dilakukan pemangkasan pada tandan bunga pertama dan tunas air. Tanaman mulai panen pada umur 10 MST. Pemanenan tomat dilakukan dengan masa panen satu bulan. Pemanenan tomat dilakukan delapan kali pemetikan, dengan frekuensi panen 3-5 hari sekali.

Tabel 1. Pengaruh perlakuan mulsa pada serangan penyakit layu Fusarium

\begin{tabular}{lc}
\hline Perlakuan & Persentase Serangan (\%) \\
\hline Tanpa Mulsa & 31.0 \\
MPHP & 27.0 \\
70 HSbT & 3.0 \\
49 HSbT & 4.0 \\
28 HSbT & 14.0 \\
7 HSbT & 21.0
\end{tabular}

Keterangan: MPHP = Mulsa Plastik Hitam Perak; HSbT = Hari Sebelum Tanam tomat

\section{Pertumbuhan Arachis pintoi Daya Tumbuh Arachis pintoi}

Gambar 1 menunjukkan bahwa daya tumbuh tanaman $A$. pintoi menggunakan stek batang rendah dengan rata-rata kurang dari $80 \%$. A. pintoi dapat tumbuh baik pada suhu $22{ }^{\circ} \mathrm{C}$ dan $28{ }^{0} \mathrm{C}$ dengan curah hujan $>1000 \mathrm{~mm}$ tahun $^{-1}$. Rendahnya daya tumbuh $A$. pintoi terutama pada perlakuan 1 MSbT dikarenakan pada awal pertumbuhan $A$. pintoi curah hujan pada bulan April yaitu sebesar $42.9 \mathrm{~mm}$. Akibatnya 
pertumbuhan $A$. pintoi kurang optimal karena kurang tersedianya air untuk awal pertumbuhan.

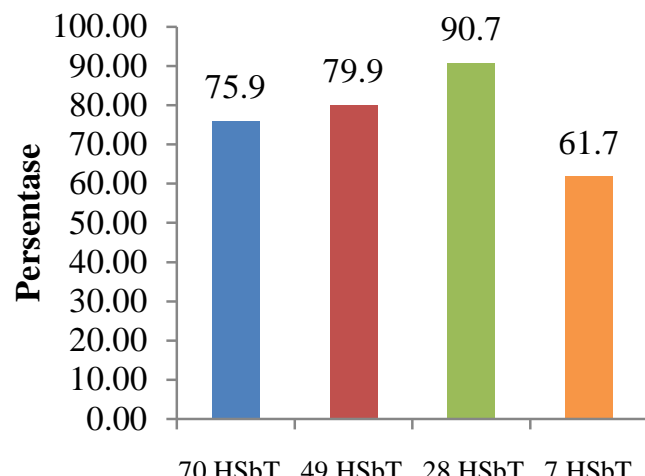

Waktu Tanam

Keterangan: HSbT $=$ Hari Sebelum Tanam tomat

Gambar 1. Daya tumbuh tanaman Arachis pintoi

\section{Penutupan Arachis pintoi}

Perlakuan 70 HSbT memberikan hasil persentase penutupan pintoi paling tinggi sebesar $98.33 \%$ pada 90 hari setelah tanam (HST). Penutupan A. pintoi sebesar $100 \%$ dapat diperoleh setelah umur tanaman lebih dari 90 HST (Gambar 2). Kecepatan tumbuh $A$. pintoi pada percobaan ini lambat, sehingga pertumbuhan gulma lebih cepat karena daya saing $A$. pintoi yang rendah.

Rendahnya kecepatan $A$. pintoi menutup tanah diduga karena populasi $A$. pintoi yang kurang rapat. Menurut Huang et al. (2004), penggunaan jarak tanam $A$. pintoi dengan jarak $10 \mathrm{~cm} \times 10 \mathrm{~cm}$, penutupannya mencapai $49 \%$ di daerah bukit (tanah tandus, $0.5 \% \mathrm{BO}$ ) pada $30 \mathrm{HST}, 87 \%$ pada $45 \mathrm{HST}, 91 \%$ pada $60 \mathrm{HST}$, sedangkan di areal taman (tanah subur, $1.5 \%$ BO) penutupannya mencapai $80 \%$ pada 30 HST.

\section{Pengaruh Perlakuan Mulsa terhadap Pertumbuhan Gulma}

Pada bedengan dengan tomat berumur 60 HST, mulsa plastik hitam perak relatif lebih efektif menekan pertumbuhan gulma terhadap bobot kering total (2.89 g), dibandingkan perlakuan biomulsa A. pintoi 70 HSbT (126.47 g) dan 49 HSbT (110.54 g) yang kurang efektif menekan pertumbuhan gulma (Tabel 2). Demikian juga terhadap jumlah spesies gulma yang terdapat pada petak percobaan.
Perlakuan biomulsa $A$. pintoi tidak dapat menekan gulma secara efektif. Hal ini dikarenakan kecepatan penutupan yang rendah memberikan peluang gulma untuk tumbuh dengan baik, sehingga $A$. pintoi tidak mampu berkompetisi dengan gulma dalam memperebutkan ruang tumbuh maupun unsur hara.

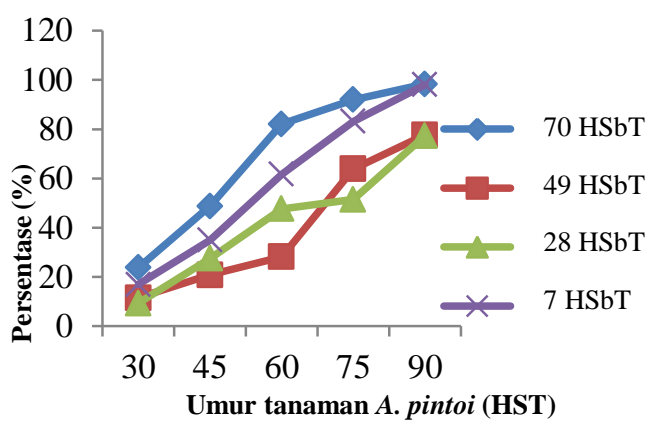

Keterangan: HSbT $=$ Hari Sebelum Tanam tomat Gambar 2. Daya tumbuh tanaman Arachis pintoi

Tabel 2. Pengaruh perlakuan mulsa terhadap jumlah spesies dan bobot kering total gulma

\begin{tabular}{|c|c|c|c|c|}
\hline \multirow[t]{3}{*}{ Perlakuan } & \multicolumn{2}{|c|}{$\begin{array}{l}\text { Jumlah } \\
\text { Spesies }\end{array}$} & \multicolumn{2}{|c|}{$\begin{array}{c}\text { Bobot Kering } \\
\text { Gulma Total } \\
\text { (gram) }\end{array}$} \\
\hline & 30 & 60 & 30 & 60 \\
\hline & HST & HST & HST & HST \\
\hline \multicolumn{5}{|l|}{ Tanpa } \\
\hline Mulsa & 9 & 8 & 21.85 & 90.83 \\
\hline MPHP & 4 & 2 & 5.17 & 2.89 \\
\hline $70 \mathrm{HSbT}$ & 12 & 11 & 84.38 & 126.47 \\
\hline 49 HSbT & 8 & 14 & 37.80 & 110.54 \\
\hline $28 \mathrm{HSbT}$ & 10 & 9 & 87.58 & 89.27 \\
\hline $7 \mathrm{HSbT}$ & 11 & 8 & 50.20 & 31.99 \\
\hline
\end{tabular}

Perlakuan mulsa plastik hitam perak menunjukkan jumlah spesies gulma terendah karena ruang tumbuh gulma lebih rendah dibandingkan dengan perlakuan biomulsa $A$. pintoi maupun perlakuan tanpa mulsa. Perlakuan biomulsa 70 hari sebelum tanam tomat menghasilkan jumlah spesies gulma yang lebih tinggi dibandingkan perlakuan 49, 28, dan 7 hari sebelum tanam tomat (Tabel 2). Gulma dominan pada perlakuan biomulsa 70 hari sebelum tanaman adalah Axonopus compressus. Menurut Severino dan Pedro (2004), A. pintoi hanya efektif untuk menekan pertumbuhan beberapa jenis 
gulma. Manglayang (2005) menambahkan bahwa salah satu kekurangan $A$. pintoi di lahan marjinal yaitu pertumbuhannya yang kurang pesat sehingga kalah berkompetisi dengan Axonopus compressus.

\section{Pengaruh Biomulsa terhadap Pertumbuhan dan Produksi Tomat}

\section{Pertumbuhan Vegetatif dan Generatif Tanaman Tomat}

Perlakuan mulsa berpengaruh nyata terhadap tinggi tanaman, jumlah daun, jumlah ruas, dan umur berbunga. Penggunaan mulsa plastik hitam perak dan biomulsa $A$. pintoi secara nyata meningkatkan tinggi tanaman tomat. Tabel 3 memperlihatkan tinggi tanaman pada perlakuan biomulsa 10 MSbT dan 7 MSbT masing-masing $43.14 \mathrm{~cm}$ dan $39.44 \mathrm{~cm}$, sedangkan pada perlakuan MPHP $41.66 \mathrm{~cm}$ perlakuan tanpa mulsa menghasilkan tanaman dengan tinggi tanaman terendah, $23.91 \mathrm{~cm}$.

Tabel 3. Rataan tinggi tanaman, jumlah daun, jumlah ruas dan umur berbunga terhadap perlakuan mulsa

\begin{tabular}{lcccc}
\hline Perlakuan & $\begin{array}{c}\text { Tinggi } \\
\text { Tanaman } \\
(\mathrm{cm})\end{array}$ & $\begin{array}{c}\text { Jumlah } \\
\text { Daun }\end{array}$ & $\begin{array}{c}\text { Jumlah } \\
\text { Ruas }\end{array}$ & $\begin{array}{c}\text { Umur } \\
\text { Berbunga } \\
(\mathrm{HST})\end{array}$ \\
\hline Tanpa & & & & \\
Mulsa & $23.91 \mathrm{c}$ & $6.0 \mathrm{~b}$ & $4.5 \mathrm{~b}$ & $46 \mathrm{~b}$ \\
MPHP & $41.66 \mathrm{a}$ & $7.1 \mathrm{ab}$ & $7.7 \mathrm{a}$ & $44 \mathrm{bc}$ \\
$10 \mathrm{MSbT}$ & $43.14 \mathrm{a}$ & $7.6 \mathrm{a}$ & $6.8 \mathrm{a}$ & $39 \mathrm{c}$ \\
$7 \mathrm{MSbT}$ & $39.44 \mathrm{a}$ & $6.9 \mathrm{ab}$ & $6.8 \mathrm{a}$ & $41 \mathrm{bc}$ \\
$4 \mathrm{MSbT}$ & $29.08 \mathrm{~b}$ & $6.4 \mathrm{~b}$ & $5.5 \mathrm{~b}$ & $47 \mathrm{ab}$ \\
$1 \mathrm{MSbT}$ & $26.47 \mathrm{bc}$ & $5.3 \mathrm{~b}$ & $5.2 \mathrm{~b}$ & $53 \mathrm{a}$ \\
\hline Keterangan: Angka yang diikuti dengan huruf yang sama pada \\
\multicolumn{5}{c}{ kolom yang sama menunjukkan tidak bebeda nyata } \\
menurut uji DMRT 5\%; MPHP = Mulsa Plastik
\end{tabular}

Demikian juga rata-rata jumlah daun dan jumlah ruas tertinggi diperoleh pada mulsa plastik hitam perak dan biomulsa 70 HSbT dan 49 HSbT. Selain itu data Tabel 3 menunjukkan bahwa perlakuan mulsa dapat mempercepat waktu pembungaan tanaman tomat. Pada percobaan ini perlakuan penanaman A. pintoi $70 \mathrm{HSbT}$ berbunga paling awal yaitu 39 HST, diikuti oleh perlakuan $49 \mathrm{HSbT}$ (41 HST) dan perlakuan MPHP (44 HST).

\section{Komponen Produksi Tanaman Tomat}

Perlakuan mulsa berpengaruh nyata terhadap komponen produksi dan produksi buah tomat. Sedangkan perlakuan tanpa mulsa konsisten menghasilkan komponen peroduksi terendah. Pada Tabel 4 dapat dilihat bahwa jumlah buah tertinggi diperoleh pada perlakuan mulsa plastik hitam perak (6.3). Meskipun demikian, ukuran buah yang dipresentasikan oleh bobot buah menunjukkan bahwa nilai tertinggi diperoleh pada perlakuan penanaman A. pintoi pada $70 \mathrm{HSbT}$ dan 49 HSbT, masing-masing $18.91 \mathrm{~g}$ dan $19.96 \mathrm{~g}$.

Sejalan dengan pengaruhnya terhadap komponen produksi, perlakuan mulsa berpengaruh nyata terhadap bobot panen per tanaman dan bobot panen per petak. Rata-rata bobot panen tertinggi diperoleh pada perlakuan mulsa plastik hitam perak (106.39 g), berbeda nyata dengan tanpa mulsa (35.19 g) dan seluruh perlakuan biomulsa. Demikian juga untuk bobot panen per petak nilai tertinggi diperoleh pada mulsa plastik hitam perak (1 $876.95 \mathrm{~g}$ ), diikuti oleh perlakuan biomulsa 49 HSbT (1 $139.73 \mathrm{~g}$ ) dan 70 HSbT (903.14 g). Perlakuan biomulsa A. pintoi 79 dan 49 HSbT juga menghasilkan bobot per buah dan rata-rata jumlah tanaman tomat lebih tinggi dibandingkan perlakuan MPHP (Tabel 4).

Tabel 4. Rataan jumlah buah dan bobot panen terhadap perlakuan mulsa.

\begin{tabular}{|c|c|c|c|c|c|}
\hline \multirow[t]{2}{*}{ Perlakuan } & \multirow{2}{*}{$\begin{array}{c}\text { Rata-rata } \\
\text { Jumlah Buah } \\
\text { Tanaman }^{-1}\end{array}$} & \multirow{2}{*}{$\begin{array}{c}\text { Rata-rata } \\
\text { Jumlah } \\
\text { Tanaman }\end{array}$} & \multicolumn{2}{|c|}{$\begin{array}{c}\text { Rata-rata } \\
\text { Bobot Panen (g) }\end{array}$} & \multirow{2}{*}{$\begin{array}{c}\text { Bobot Buah }{ }^{-1} \\
\text { (g) }\end{array}$} \\
\hline & & & Tanaman & Petak & \\
\hline Tanpa Mulsa & $2.5 \mathrm{~b}$ & $7.0 \mathrm{~b}$ & $35.18 \mathrm{c}$ & $247.99 \mathrm{~d}$ & $14.55 \mathrm{c}$ \\
\hline MPHP & $6.3 \mathrm{a}$ & $16.3 \mathrm{a}$ & $106.39 \mathrm{a}$ & $1876.59 \mathrm{a}$ & $17.47 \mathrm{abc}$ \\
\hline $70 \mathrm{HSbT}$ & $2.9 \mathrm{~b}$ & $17.0 \mathrm{a}$ & $55.48 \mathrm{bc}$ & 903.14 bc & $18.91 \mathrm{ab}$ \\
\hline $49 \mathrm{HSbT}$ & $3.5 \mathrm{~b}$ & $18.0 \mathrm{a}$ & $63.96 \mathrm{~b}$ & $1139.73 b$ & $19.96 \mathrm{a}$ \\
\hline $28 \mathrm{HSbT}$ & $3.5 \mathrm{~b}$ & $15.3 \mathrm{a}$ & $53.92 \mathrm{bc}$ & $702.37 \mathrm{~cd}$ & $16.86 \mathrm{abc}$ \\
\hline $7 \mathrm{HSbT}$ & $3.6 \mathrm{~b}$ & $13.8 \mathrm{a}$ & $55.02 \mathrm{bc}$ & $444.01 \mathrm{~cd}$ & $15.56 \mathrm{bc}$ \\
\hline
\end{tabular}


Perlakuan MPHP dan biomulsa Arachis pintoi dapat meningkatkan pertumbuhan dan produksi tanaman tomat. Perlakuan biomulsa Arachis pintoi dapat meningkatkan komponen pertumbuhan yaitu tinggi tanaman, jumlah daun, jumlah ruas, dan panjang ruas. Selain itu, perlakuan biomulsa dapat mempercepat pembungan tanaman tomat. Waktu tanam terbaik $A$. pintoi sebagai biomulsa adalah 49 atau 70 hari dibandingkan 28 atau 7 hari sebelum penanaman tomat. Hal tersebut dikarenakan penanaman $A$. pintoi pada perlakuan 49 atau 70 hari sebelum tanam menyebabkan A. pintoi dapat tumbuh lebih baik dan penutupan tanah lebih tinggi sehingga dapat mengurangi kemungkinan terjadinya kompetisi antara gulma dengan tanaman tomat.

Peningkatan pertumbuhan tanaman tomat pada perlakuan biomulsa A. pintoi dikarenakan A. pintoi sebagai tanaman penutup tanah dapat mengikat $\mathrm{N}$ bebas sehingga ketersediaan unsur hara $\mathrm{N}$ untuk tanaman tomat lebih tinggi. Selain dapat menambat nitrogen, A. pintoi yang tumbuh menutupi permukaan tanah dapat menjaga kelembaban tanah. Gardner et al. (1991) menambahkan bahwa nutrisi mineral dan ketersediaan air mempengaruhi pertumbuhan ruas, terutama oleh perluasan sel, seperti pada organ vegetatif atau organ pembuahan.

\section{KESIMPULAN}

Persentase tumbuh dan kecepatan penutupan $A$. pintoi relatif lambat karena kondisi kering pada awal penanaman sehingga kurang efektif menekan pertumbuhan gulma. Penumbuhan A. pintoi maksimum dicapai pada umur 40 hari seterlah tanam. Tanaman tomat yang ditanam dengan biomulsa $A$. pintoi 70 dan 49 hari sebelum tanam menunjukkan persentase tumbuh dan pertumbuhan yang lebih baik dibandingkan perlakuan MPHP maupun perlakuan tanpa mulsa. Perlakuan biomulsa A. pintoi 70 dan 49 hari sebelum tanam (HSbT) mampu meningkatkan komponen pertumbuhan dan produksi buah tomat. Setara dengan perlakuan mulsahitam perak, sedangkan perlakuan tanpa mulsa konsisten menunjukkan pertumbuhan dengan produksi terendah.

\section{SARAN}

Perlu dilakukan penelitian lanjutan tentang faktor-faktor yang mempengaruhi kecepatan pertumbuhan dan penutupan Arachis pintoi sebagai biomulsa.

\section{DAFTAR PUSTAKA}

Balittan. 2004. Kacang hias (Arachis pintoi) pada usaha tani lahan kering. http://balittanah. litbang.deptan.go.id. [8 Maret 2009].

Gardner, F.P., R.B. Pearce, R.L. Mitchel. 1991. Fisiologi Tanaman Budidaya. Penerbit Universitas Indonesia. Jakarta.

Gomez, K.A., A.A. Gomez. 1995. Prosedur Statistika untuk Penelitian Pertanian. Terjemahan dari: Statistical Procedures for Agricultural Research. Penerjemah: E. Sjamsudin dan J.S. Baharsjah. Penerbit Universitas Indonesia. Jakarta.

Havlin, J.L., J.D. Beaton, S.L. Tisdale, W.L. Nelson. 1999. Soil Fertility and Fertilizers An Introduction to Nutrient Management. 6th ed. Prentice Hall. Upper Saddle River. New Jersey.

Huang Yi-bin, Tang Long-fei, Zheng Zhongdeng, Chen En, Ying Zhao-yang. 2004. Utilization of Arachis pintoi In Red Soil Region and Its Efficiency on Water-Soil Conservation in China. 13th International Soil Conservation Organisation Conference.

Izhar, L., A.D. Susila. 2010. Rekomendasi pemupukan fosfor dan natrium berdasarkan analisis hara tanah pada tanaman sayuran. J. Hort. Indonesia 1(2): 81-87.

Kartapradja, R., D. Djuariah, 1992. Pengaruh tingkat kematangan buah tomat terhadap daya kecambah, pertumbuhan dan hasil tomat. Buletin Penelitian Hortikultura Vol $\mathrm{XXIV} / 2$.

Kartika, J.G., M.R. Reyes, A.D. Susila. 2009. Review of literature on perennial peanut (Arachis pintoi) as potential cover crop in the Tropics. Kumpulan Makalah Seminar Ilmiah (ed. A.D. Susila et al.,). Perhimpunan 
Hortikultura Indonesia. Bogor. hal 391399.

Nurjaya, I.G.M. Oka. 2006. Competition between some grass and legume species with Axonopus compressus (Swartz) P. Beauv. Under reduced light intensity. http:// ejournal.unud.ac.id/abstrak/igm.\%20oa $\% 2$ 0nurjaya\%20_sdh_\%2 rtf.pdf. [8 Agustus 2010].

Rosliani, R., Y. Hilman, N. Nurtika. 2002. Pengaruh tanaman penutup tanah dan mulsa limbah organik terhadap produksi mentimun dan erosi tanah. J. Hortikultura. 12(2): 81-87.

Severino, F. J., Pedro J. C. 2004. Weed supression by smother crops and selective herbicides. Sci. Agric. (Piracicaba, Braz.). 61(1): 2126.

Sukman, Y., Yakub. 2002. Gulma dan Teknik Pengendaliannya. PT. Raja Grafindo Persada. Jakarta. 